\title{
Nanotechnology Approaches for Antiretroviral Drugs Delivery
}

\author{
Iannazzo $\mathrm{D}^{*}$, Pistone $\mathrm{A}^{1}$, Romeo $\mathrm{R}^{2}$ and Giofrè $\mathrm{SV}^{2}$ \\ ${ }^{1}$ Department of Electronic Engineering, Chemical and Industrial Engineering, University of Messina, Messina, Italy \\ ${ }^{2}$ Department of Pharmaceutical Sciences and Health Products, University of Messina, Messina, Italy
}

${ }^{*}$ Corresponding author: Iannazzo D, Department of Electronic Engineering, Chemical and Industrial Engineering, University of Messina, Contrada Di Dio, Messina, Italy, E-mail: diannazzo@unime.it

Citation: Iannazzo D, Pistone A, Romeo R, Giofrè SV (2015) Nanotechnology Approaches for Antiretroviral Drugs Delivery. J Aids Hiv Infec 1(2): 201. doi: 10.15744/2454-499X.1.201

Received Date: March 25, 2015 Accepted Date: July 07, 2015 Published Date: July 09, 2015

\begin{abstract}
The development of effective drug delivery approaches for the treatment of AIDS and HIV infection is a global challenge. The advent of multidrug, highly active antiretroviral therapy (HAART), have increased the life span of HIV-infected patients. However, it has not eradicated HIV infections, particularly in anatomically privileged sites, such as the brain, testes, gut, liver, kidney, and secondary lymphoid tissue. Several nanocarriers have been investigated in order to enhance the effective delivery of antiretroviral drugs for HIV prevention and therapy. This review focuses on the most recent and significant examples of nanotechnology-based approaches for the delivery of antiretroviral agents belonging to the classes of nucleoside-analog reverse transcriptase inhibitors (NRTIs) and nonnucleoside reverse transcriptase inhibitors (NNRTIs). Nanocarriers such as natural and synthetic polymeric nanoparticles, dendrimers, liposomes, and various drug conjugates have been discussed. These nanotechnology carriers are able to deliver the antiretroviral agents in a controlled and/or targeted manner thereby increasing the drug bioavailability and residence time at target sites with a considerable improvement in quality of HIV patients.
\end{abstract}

Keywords: Nanotechnology; Anti-HIV agents; Drug Delivery Systems

\section{Introduction}

Human immunodeficiency virus (HIV), the etiological agent of acquired immunodeficiency syndrome (AIDS), is responsible for more than 25 million deaths worldwide and estimated 34 million people are infected with HIV across the globe with consequently devastating socioeconomic effects [1]. The disease is characterized by severe impairment of immune system resulting in markedly decreased $\mathrm{CD}^{+} \mathrm{T}$ cells, thus leading to various life-threatening opportunistic infections. After the interaction of its exterior glycoprotein gp120 with CD4 ${ }^{+}$of T cells, HIV most commonly uses the chemokine CCR5 and/or CXCR4 as a co-receptor to enter the target cells. Then, the genetic RNA material together with enzymes such as the reverse transcriptase, integrase, ribonuclease and protease are released into the host cell $[2,3]$. Among the different enzymes, reverse transcriptase (RT) represents one of the main targets for the development of AIDS therapy [4,5]. Inhibitors of reverse transcriptase both nucleoside analogues and non-nucleoside have been described but all present some limitations including toxicity and the emergence of resistant strains $[6,7]$. With the advent of multidrug, highly active antiretroviral therapy (HAART), the prognosis for HIV-1 infected patients has significantly improved; however, it has not eradicated HIV infection, particularly in sequestered, anatomically privileged sites, such as the brain, testes, gut, liver, kidney, and secondary lymphoid tissue [8]. Additionally, emergence of resistant viral strains and the adverse side effects associated with prolonged use continue to slow down the application of effective antiviral therapies [9]. Moreover, these drugs suffer from physicochemical problems such as poor solubility permeability, and stability which may lead to formulation development problems and impair optimal absorption, biodistribution, and sustained antiretroviral effect. In order to overcome these problems, several new chemical entities or improved delivery systems have been proposed involving the use of several nanotechnology-based delivery systems [10-14]. Thus, in order to improve HIV therapy, a large number of carriers have been developed; they include polymeric nanoparticles, solid lipid nanoparticles, liposomes, nanoemulsions, dendrimers, and drug conjugates [15-20]. These nanotechnology carriers are able to deliver the HIV current drugs in a controlled and/or targeted manner thereby increasing the drug bioavailability and residence time at target sites with a considerable improvement in life quality of HIV patients. Moreover, research in this field suggest that nanotechnology-based drug delivery systems have the potential to facilitate complete eradication of viral load from the reservoir sites such as the central nervous system, the cerebrospinal fluid, the lymphatic system and in the macrophages, where it cannot be reached by the majority of therapeutic agents in adequate concentrations or in which the therapeutic agents cannot reside for the necessary duration [21]. This review will focus the most recent and significant examples of nanotechnology-based approaches for the delivery of the main drugs used in the standard antiretroviral therapy (ART) with particular emphasis on their safety, pharmacokinetic aspects, and long-term toxicity. 


\section{Overview of antiretroviral drugs used for treatment of HIV/AIDS}

To date, an arsenal of 28 Food and Drug Administration (FDA) approved drugs are available for treatment of HIV-1 infections. These drugs are mainly distributed into six distinct classes based on their molecular mechanism: 1) nucleoside-analog reverse transcriptase inhibitors (NRTIs); 2) non-nucleoside reverse transcriptase inhibitors (NNRTIs); 3) integrase inhibitors; 4) protease inhibitors (PIs); 5) fusion inhibitorsand 6) co-receptor antagonists. Moreover, FDA approved a combination of HIV medicines containing two or more HIV drugs from one or more of the reported drug classes [22]. Reverse transcriptase (RT) plays a key role in the replication of HIV by converting single-stranded genomic RNA into double-stranded proviral DNA and represents one of the main targets for the development of AIDS therapy [23-28]. Both NRTIs and NNRTIs inhibit the RT-associated polymerase activity: the NRTIs compete with the natural deoxynucleotide triphosphate (dNTP) substrate and act as chain terminators, while the NNRTIs bind to an allosteric pocket and inhibit polymerization noncompetitively; in addition to these two classes, other RT inhibitors (RTIs) target RT by distinct mechanisms [29]. After the discovery of zidovudine (AZT) in 1987, NRTIs were the first class of drugs to be approved by the FDA; they play a central role in HAART and have been used extensively in the fight against HIV-1 infection. NRTIs, nucleoside analogues lacking of the 3'-hydroxyl group or modified at the sugar moiety, are administered as inactive prodrugs and require metabolic conversion to their corresponding active 5 '-triphosphate forms by host cellular kinases. Thus, competing with the natural deoxynucleoside triphosphates (dNTPs), these drugs can be efficiently incorporated at the 3'-end of the viral DNA as NRTI monophosphate by HIV-1 RT. After incorporation, these nucleoside analogues inhibit the elongation of viral DNA chain, preventing the incorporation of next incoming nucleotide, resulting in termination of the growing viral DNA chain [30]. In the last year, to search new biologically active nucleoside analogues, structural modifications on the sugar moiety and/ or the heterocyclic base of natural nucleosides have been performed in order to overcome the drawbacks mainly due to enzymatic degradation and/or to reduce the toxicity and the cross-resistance problems [31-40]. Currently, there are eight FDA-approved NRTIs: abacavir (ABC), didanosine (ddI), emtricitabine (FTC), lamivudine (3TC), stavudine (d4T), zalcitabine (ddC), zidovudine (AZT), and tenofovir disoprovil fumarate (TDF), a nucleotide RT inhibitor (Figure1). The commonly used pyrimidine analogues are AZT (3'-azido-2',3'-dideoxythymidine) and d4T (2',3'-dideoxy-2',3'-didehydrothymidine), analogues of thymidine, 3TC ( $\beta$-1$(-)-2,3^{\prime}$-dideoxy-3'-thiacytidine) and FTC ( $\beta$-1-(-)-2',3'-dideoxy-5-fluoro-3'-thiacytidine), analogues of 2'-deoxycytidine. Purine analogues commonly used in HAART are $\mathrm{ddI}\left(\beta-\mathrm{d}-(+)-2^{\prime}, 3^{\prime}\right.$-dideoxyinosine $)$, a 2'-deoxyadenosineanalogue, ABC ((-)-(1S,4R)4-[2-amino-6-(cyclopropylamino)-9H-purin-9-yl] -2-cyclopentene-1-methanol), a 2'-deoxyguanosine analogue and TDF (R-9(2-phosphonomethoxy propyl) adenine), a chemically unique acyclic phosphonate nucleotide analogue. As with all antiretroviral therapies, treatment with any of these agents often results in the emergence of HIV-1 strains with reduced drug susceptibility.

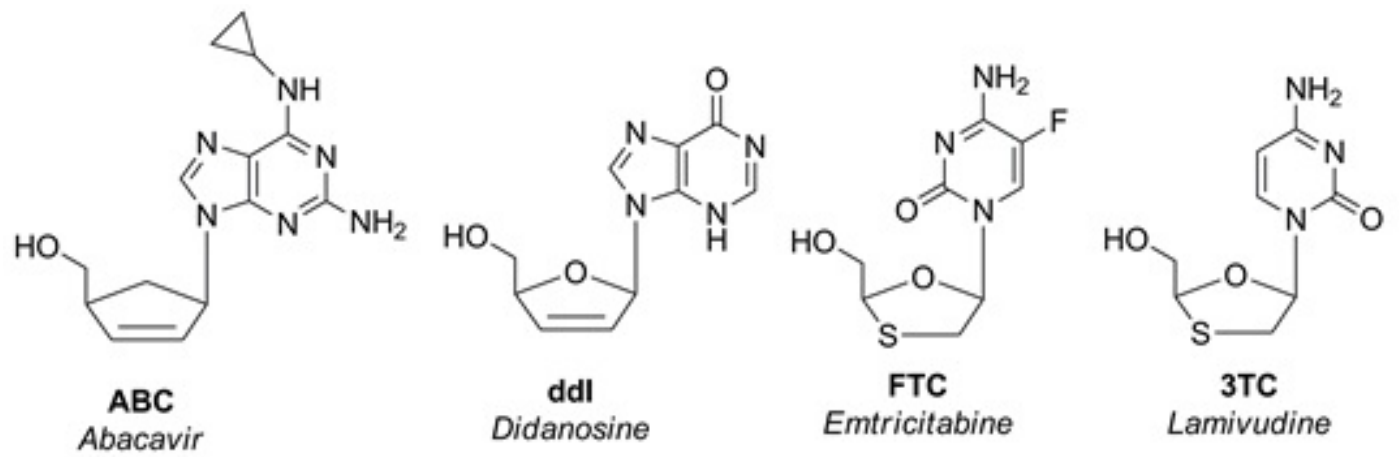<smiles>Cc1cn(C2C=CC(CO)O2)c(=O)[nH]c1=O</smiles><smiles>Nc1ccn(C2CCC(CO)O2)c(=O)n1</smiles>

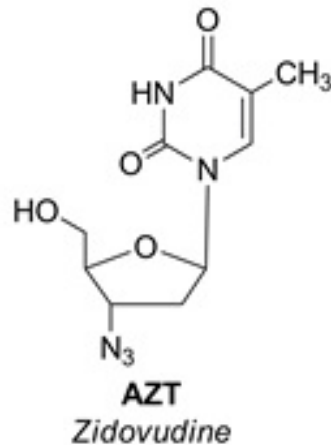<smiles>CC(Cn1cnc2c(N)ncnc21)OCP(=O)(O)O[Na]</smiles>

Figure 1: Nucleotide reverse transcriptase inhibitors approved by FDA

Resistance to NRTIs is mediated by two main mechanisms. The first is the prevention of NRTI incorporation into the nascent chain; this mechanism involves discriminatory mutations able to weaken the binding affinity of the NRTIs and retaining the binding efficiency of the corresponding natural nucleosides; thus, the incorporation of NRTIs into the viral DNA is reduced and the virus continues to proliferate. The second common mechanism of resistance to NRTIs, is the nucleotide excision which represents the reversal of the polymerization reaction in order to restore the DNA synthesis. RT utilizes ATP or inorganic pyrophosphate (PP $)$ as a co-substrate to remove the incorporated nucleoside analogue monophosphate thus terminating the DNA elongation [41,42]. 
The non-nucleoside reverse transcriptase inhibitors (NNRTIs) are structurally and chemically different molecules able to bind in noncompetitive manner to a hydrophobic RT pocket close to the polymerase active site. Unlike NRTIs, these drugs do not require intracellular metabolism to exert their activity. The binding of NNRTIs changes the spatial conformation in the proximity of the active site upon binding to the hydrophobic NNRTI-binding pocket (NBP), thus inducing rotamer conformational changes in some residues of RT (Y181 and Y188). This binding makes the thumb region more rigid, thus reducing the polymerase activity and blocking the DNA synthesis [43]. More than thirty different classes of compounds could be considered to be NNRTIs and currently, there are four approved NNRTIs: etravirine (ETV), delavirdine (DLV), efavirenz (EFV), and nevirapine (NVP), and several in development, including rilpivirine (RPV) in phase 3 (Figure2).<smiles>Cc1cc(C#N)ccc1Oc1nc(Nc2ccc(C#N)cc2)nc(N)c1Br</smiles>

ETV Etravirine<smiles>CC(C)Nc1cccnc1N1CCN(C(=O)c2cc3cc(NS(C)(=O)=O)ccc3[nH]2)CC1</smiles>

DLV Delavirdine<smiles>CC1(C#CC2CC2)OC(=O)Nc2ccc(Cl)cc21</smiles>

EFV<smiles>O=C1Nc2cccnc2N(C2CC2)c2ncccc21</smiles>

NVP

Nevirapine

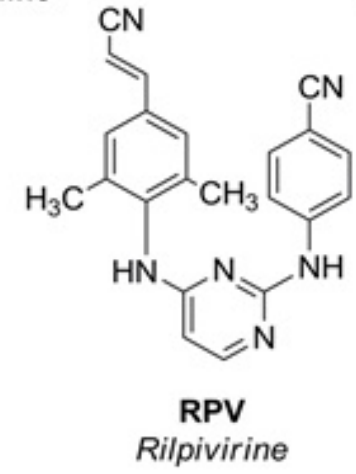

Figure 2: Non-Nucleoside Reverse Transcriptase Inhibitors approved by FDA

NNRTIs represent a pivotal part of HAART because of their minimal side effects and less toxicity profiles compared to NRTIs [44]. However, as with NRTI, complex patterns of NNRTI-resistant mutations diminish or completely abolish their therapeutic efficacy. Several factors are involved in the NNRTI resistance such as the ease of sequence variability in residues aligning the NBP, the effect of resistance mutations on drug susceptibility and viral fitness. NNRTI resistance generally results from amino acid substitutions such as L100, K101, K103, E138, V179, Y181, and Y188 in the NNRTI-binding pocket of RT [45]. First-generation inhibitors including nevirapine and delavirdine, have a lower genetic barrier to resistance and resistance mutations emerge quickly with respect to the second-generation inhibitors. Primary resistance mutations that are selected by these drugs are all located in the NBP, and reduce the binding affinity of the inhibitors or block their access to NBP. Second-generation NNRTIs, such as efavirenz usually require two or more mutations in the HIV-1 RT before significantly decreasing their antiviral potency [46]. Third generation compounds etravirine and rilpivirine have enhanced potency and effectiveness on drug-resistant mutants [47]. Most NNRTI mutations engender some level of cross resistance among different NNRTIs, especially in the context of additional secondary mutations. The development of resistance to the different classes of approved drugs led to resistance testing performed in order to select a combination of drugs that is most effective for each patient. In addition, extremely lengthy regimens of HAART are related to poor patient compliance, drug intolerance, toxicity and viral relapse after some time [48]. Side effects due to the drugs toxicities are also a concern; patients treated with HAART showed increased rates of heart disease, diabetes, liver disease, cancer and accelerated aging. Even if these side effects could be related to the HIV infection itself or to co-infection with another virus, such as hepatitis $\mathrm{C}$ virus, resulting in liver disease, the toxicities resulting from the drugs used in HAART could also contribute to these effects [49]. Other than these effects, the disease management is challenging due to the presence of viral reservoir sites that are inaccessible to the existing drug delivery methods and the presence of latent cells with integrated HIV DNA which are susceptible to in vivo activation at a later stage. The main reason for these effects is related to hidden reserves of HIV viruses; these 'latent reservoirs' are $\mathrm{CD}^{+} \mathrm{T}$ cells and cells of the macrophage-monocyte lineage [50]. These cells are typically concentrated in specific anatomic sites, such as secondary lymphoid tissue, testes, liver, kidney, lungs, gut and the CNS [51,52]. It was recently demonstrated that these latent reservoirs, contribute to the generation of elusive mutant viral genotypes by serving as the host for viral genetic recombination [53]. Thus, the complete eradication of the virus from such reservoirs is a pivotal issue for an effective longterm HIV therapy. On the basis of these considerations there is a great need to explore new approaches for developing lowerdosage treatment modalities that provide more sustained dosing coverage with reduced toxicity and able to effectively eradicate the virus from the reservoirs, avoiding the need for lifetime treatments. 


\section{Nanotechonology approaches for antiretroviral drugs delivery}

Nanotechnology has shown tremendous applications in healthcare promising better alternatives to diagnose and treat AIDS. HIV nanotherapeutics has the potential to sustained release, increased half life, higher drug concentrations at target sites and lesser side effects. Moreover these approaches also targets latent HIV in anatomically privileged sites. The purpose of this review is to present highlight of recent developments in the application of nanotechnology for the delivery of antiretroviral drugs which represent today the main drugs used in HAART for HIV treatment. The wide range of different materials used as cargo for these drugs, share their submicron dimensions (from a few nanometers up to 1 micrometer) but substantially differ in physical-chemical properties, biological behavior, preparation methods and characterization methodologies. Thus the different nanotherapeutics will be discussed with respect of the kind of nanomaterial used. In table 1 is reported a summary of the recent HIV-1 nanotherapeutics antiretroviral drugs based.

\begin{tabular}{|c|c|c|c|c|c|}
\hline \multicolumn{2}{|c|}{ Nanomaterial } & \multirow{2}{*}{$\begin{array}{c}\text { Antiretroviral drug } \\
\mathrm{D} 4 \mathrm{~T}\end{array}$} & \multirow{2}{*}{$\begin{array}{c}\text { Testing way } \\
\text { in vitro }\end{array}$} & \multirow{2}{*}{$\begin{array}{c}\text { Cells/tissue/ organs } \\
\text { macrophages }\end{array}$} & \multirow{2}{*}{$\begin{array}{c}\text { Ref. } \\
56\end{array}$} \\
\hline Synthetic polymers & PLGA & & & & \\
\hline & PBCA, MMA-SPM & $\mathrm{D} 4 \mathrm{~T}$ & in vitro & (BMVECs) & 57 \\
\hline & PBCA, MMA-SPM & AZT, 3TC & in vitro & BBMECs & 58 \\
\hline & PBCA, MMA-SPM & D4T, DLV & in vitro & HBMECs & 59 \\
\hline & Eudragit RL 100 & $\mathrm{AZT}$ & exvivo & Wistar rat skin & 60 \\
\hline & PLGA & AZT, 3TC & in vivo & mice & 61 \\
\hline & PHIC & $\mathrm{AZT}$ & exvivo & lymphoid tissue & 62 \\
\hline & PHCA & $\mathrm{AZT}$ & in vitro & macrophages & 63 \\
\hline & PPG-5-CETETH-20 & $\mathrm{AZT}$ & in vitro & release study- & 64 \\
\hline & PLA, PLA-PEG & $\mathrm{AZT}$ & in vitro & macrophages & 65,66 \\
\hline & PLGA & $3 \mathrm{TC}$ & in vitro & HepLL & 67 \\
\hline & PMAA & $3 \mathrm{TC}$ & in vitro & release study & 68 \\
\hline & poloxamer 388/ & RPV & in vivo & mice and dogs & 69,70 \\
\hline & PLGA & NVP & in vitro & HBMECs & 71 \\
\hline & polysaccharide, PEG & NVP & in vivo & mice & 72 \\
\hline & PLGA & EFV & in vivo & PBMCs & 73,74 \\
\hline & PCL or PEO & DPV & ex vivo & pig mucosa & 75 \\
\hline \multirow[t]{4}{*}{ Natural polymers } & chitosan & $3 \mathrm{TC}$ & in vitro & release study & 77,78 \\
\hline & squalene & ddC, ddI & in vitro & PBMCs & 80 \\
\hline & mannosylated gelatin & $\mathrm{ddI}$ & in vivo & mice & 81 \\
\hline & chitosan & $\mathrm{D} 4 \mathrm{~T}$ & in vitro & release study & 82 \\
\hline \multirow[t]{2}{*}{ Dendrimers } & mannosylated dendrimer & $3 \mathrm{TC}$ & in vitro & macrophages & 88 \\
\hline & tuftsindendrimers & EFV & in vitro & monoc/ macroph & 89,90 \\
\hline \multirow[t]{11}{*}{ Liposomes } & liposomes & ddCTP & in vitro & monoc/ macroph & 95 \\
\hline & liposomes & AZT & in vivo & mice & 96,97 \\
\hline & galactosylated liposomes & $\mathrm{AZT}$ & in vivo & mice & 98,99 \\
\hline & mannosylated liposomes & $\mathrm{AZT}$ & in vivo & mice & 100 \\
\hline & liposomes & $\mathrm{D} 4 \mathrm{~T}$ & in vitro & macrophages & 101 \\
\hline & mannosylated liposomes & $\mathrm{D} 4 \mathrm{~T}$ & in vitro & macrophages & 102 \\
\hline & galactosylated liposomes & $\mathrm{D} 4 \mathrm{~T}$ & in vitro & monoc/ macroph & $103-106$ \\
\hline & liposomes & ddI & in vitro & U937 & 108 \\
\hline & liposomes & ddIMP & in vitro & PBMCs & 111 \\
\hline & liposomes & $\mathrm{ddC}$ & in vitro & U937 & 114 \\
\hline & liposomes & ddCMP & in vitro & monoc/ macroph & $116-118$ \\
\hline \multirow[t]{4}{*}{ Miscellaneous } & cyclodextrin & EFV & in vitro & U937 & 120 \\
\hline & micelles P85 & AZT,3TC & in vitro & macrophages & 123 \\
\hline & macrophages & EFV & in vitro & monocytes & 126 \\
\hline & CNT & $3 \mathrm{TC}$ & in vitro & MT-4 & 20 \\
\hline
\end{tabular}

Table 1: Summary of HIV-1 Nanotherapeuticsantiretroviral drugs based 


\section{Synthetic polymeric nanoparticles}

Polymers are the essential component of nanocarriers and almost $90 \%$ of the controlled and sustained drug delivery devices essentially contain polymers as vital component. Synthetic polymeric nanoparticles such as poly (lactic-co-glycolic acid) (PLGA) or polylactide, polymethacrylic acid, polyethylene glycol (PEG), all of which are biodegradable, are prepared from synthetic polymers where drugs are dissolved, entrapped, or encapsulated [54]. Synthetic polymers have a precise chemical composition and high predictable physical properties such as controlled rate of disassociation, permeability, degradation, erosion and targeting capability. Advances in polymerization chemistries and the application of orthogonal chemical modification reactions led to the development of advanced multifunctional polymeric nanoparticles with precise control over the architectures of the individual polymer components, in order to direct their assembly and subsequent transformations into nanoparticles of selective overall shapes, sizes, morphologies, external surface charges. Moreover, the insertion of selected functionalities can modulate the responsiveness of the nanostructures to specific stimuli through remote activation [55]. Sumit and co-workers reported an in vitro study on colloidal gold-loaded, poly (d,l-lactic-co-glycolic acid)-based nanoparticles containing stavudine [56]. The authors report a drug release for a prolonged period (over 63 days) and the uptake of these nanoparticles by macrophages. This nanosystem may minimize the systemic toxicity of stavudine, providing reduced required drug dose and improved drug delivery to macrophages over an extended period. The nanoformulation of polybutylcyanoacrylate (PBCA) and methyl methacrylate-sulfopropyl methacrylate (MMA-SPM) nanoparticles for brain targeting was investigated by Kuo et al. on several antiretroviral agents. The authors initially reported the loading of stavudine in the nanoformulation by using an in vitro brain microvascular endothelial cell model [57]. In a successive studythe same research team evaluated the effect of size of PBCA and MMA-SPM nanoparticles on the permeability of zidovudine and lamivudine across the blood-brain barrier (BBB) [58]. The permeability of these drugs was found to be inversely proportional to nanoparticle size; the authors report values of permeability of AZT and 3TC, respectively 8-20-fold and 10-18-fold higher with PBCA nanoparticles, whereas for MMA-SPM nanoparticles a 100\% increase in the BBB permeability was observed for both drugs. In a subsequent report, the transport of stavudine, delavirdine, and saquinavir across the BBB when delivered as PBCA and MMA-SPM nanoparticles was investigated [59]. The results revealed that the permeability of all the investigated drugs increased about 12-16-fold with PBCA nanoparticles and 3-7-fold with MMA-SPM nanoparticles. The team of Avrim investigated the role of monolithic film of Eudragit RL 100 and ethyl cellulose for transdermal application of zidovudine and compared the release profiles [60]. The authors showed for Eudragit RL100 based delivery the highest in vitro cumulative release profile giving the closest results with the freedrug; this effect could be attributed to the hydrophilic natureand swelling of ERL polymer. In contrast, drug releasefrom hydrophobic ethyl cellulose film, not swellable, was slower. Synthetic nanoparticle has been investigated for the delivery of zidovudine-lamivudine combination [61]. The nanosystem was prepared through emulsion polymerization in a continuous aqueous phase of different polymers such as poly (lactic-co-glycolic acid) (PLGA), poly (lactic acid), and poly (methyl methacrylate) (PMMA), methyl methacrylate sulfopropyl methacrylate (MMASPM). The authors observed that in vitro drug release was higher from PLGA compared to the other nanoparticles. For both the investigated drugs, release from PLGA nanoparticles was greater than 95\% within 10 hours and acute toxicity to animal cells was not detected. Dembri et al. reported the preparation of poly (isohexylcyanate) nanoparticles of zidovudine for the targeting of lymphoid tissue in the gastrointestinaltract [62]. From this study the drug levels of the synthesized carrier resulted in the Peyer's patches four times higher with the encapsulated drug form, when compared with aqueous drug solution. In a separate study, Lobenberg et al formulated polyhexylcyanoacrylate nanoparticles always for the delivery of zidovudine [63]. A controlled AZT release and improved AZT incorporation into the target tissues was reported by Carvalho et al using as delivery system a PPG-5CETETH-20/oleic acid/water composition [64]. Mainardes and co-workers encapsulated AZT on biodegradable poly (L-lactide) or poly (L-lactide)-poly (ethylene glycol) blend by the double-emulsion solvent-evaporation method [65]. The authors report that the PEG presence influenced all of the analyzed physicochemical parameters and that the amount of drug released increases with the PEG presence in the blend. The same research team in a similar study showed intranasal delivery as an effective route for administration of AZT by PLA and PLA-PEG blend NPs [66]. They reported that PLA and PLA-PEG blend had same morphology but particle size and zeta potential were changed by PEG. The relative bioavailability of AZT-loaded PLA-PEG nanoparticle was 2.7 times more relative to AZT-loaded PLA nanoparticle and 1.3 times more relative to aqueous solution formulation, thereby depicting PLA-PEG blend NPs as potential carrier of drug via intranasal route.

These in vivo studies in rodents demonstrated also in this case, higher zidovudine levels in the body with the encapsulated drug compared with free drug solution after oral administration. Wang and co-workers reported PLGA nanoparticles loaded with lamivudine and coated with BSA prepared via a double emulsion method [67]. The loaded lamivudine showed a burst release at beginning and sustained release until $24 \mathrm{~h}$ in physiological conditions while the PLGA particles were readily internalized into the human liver cells within a short time and increased gradually with the prolongation of incubation time regardless of the loading of lamivudine. Tamirhrashi et al. prepared polymethyl acrylic acid nanoparticle loaded with lamivudine [68]. The nanoparticle showed a slow and constant release of the drug with constant drug plasma concentration, thus increasing therapeutic efficacy. A nanoformulation of rilpivirine, a second generation NNRTI with a half-life of 38 hours, was stabilized by polyethylenepolypropylene glycol (poloxamer 338) and PEGylatedtocopheryl succinate ester (TPGS 1000) [69,70]. The nanotherapeutic, administered as single intramuscular or subcutaneous injection in mice and dogs, resulted in sustained release over 3 months in dogs and 3 weeks in mice. Its pharmacokinetics, disposition to lymphoid tissues and tolerability were evaluated for its use as once- 
monthly drug in humans, thus demonstrating the potential of this long acting drug formulation for improving the compliance in HIV patients and prophylaxis against HIV transmission. Kuo et al., prepared Poly (lactide-co-glycolide) (PLGA) nanoparticle grafted with transferrin as efficient carriers for enhanced transport across Human Brain Microvascular Endothelial Cells (HBMEC) for viral therapy [71]. NVP nanosuspensions with surface modification via albumin, polysaccharide and PEG to enhance its targeting potential, were prepared by Sheqokaret al. These surface coated nanosuspensions, when administered intravenously in rats, showed enhanced bioavailability, antiretroviral drug accumulation and prolonged residence in organs such as brain, liver and spleen compared to free drug [72]. One example of the work in this area is the PLGA nanoparticles containing multiple antiretroviral drugs (ritonavir, lopinavir, and efavirenz) which were fabricated by Destache et al using a multiple emulsion solvent evaporation technique [73]. The encapsulated antiretrovirals were detected intracellularly in peripheral blood mononuclear cells in vitro after 28 days. On the contrary, unencapsulated antiretrovirals could not be detected after two days. It was showed that nanoparticles based delivery of single dose of lopinavir/ritonavir and efavirenz resulted in better and sustained suppression of the HIV-1 from both serum and tissues compared to free drugs administration in mice model. Moreover it was demonstrated that parenteral delivery of antiretroviral drugs is possible and hence overcome the issue of absorption and metabolism with the resultant improvement in bioavailability of these drugs. In a similar work, the same research team investigated PLGA nanoparticles containing efavirenz (EFV) and boosted lopinavir (lopinavir/ritonavir; LPV/r) by a high-pressure homogenization method [74]. The authors demonstrated the significant uptake of the combination of antiretroviral drugs particles compared to the soluble free antiretroviral drugs, the subsequent release of levels of antiretroviral drugs in the nuclear, cytoskeleton, and membrane fractions of cells with no toxicity for 28 days. In a recent work, Das Neves and co-workers prepared differently surfaceengineered poly ( $\varepsilon$-caprolactone) nanoparticles and tested their ability to modulate the permeability and retention of dapivirine in cell monolayers and pig vaginal and rectal mucosa [75]. This nano formulation increased monolayer/tissue drug retention as compared to unformulated dapivirine. Cell and tissue toxicity was also affected differently by nanoparticles; the PEO modification decreased the in vitro toxicity of dapivirine, while highertoxicity was generally observed for the same systems coated with sodium lauryl sulfate (SLS) or with cetyltrimethylammonium bromide (CTAB).

\section{Natural polymers}

Together with synthetic polymers, natural polymers such as cellulose, gelatin pullulan, chitosan, alginate and gliadin, represent the predominant types of nanoparticles that are typically used for biological applications. They are very biodegradable polymers where the biologic active agents can be dissolved, entrapped, or encapsulated. Unlike synthetic polymers, the natural polymers widely vary in physical and chemical composition [12,14,76]. Lavimudine loaded chitosan nanoparticle were prepared by ionic gelation of chitosan with tripolyphosphate anion [77]. The developed system showed sustained release over 24 hrs which was more efficient than lamivudine conventional dosage forms. Surfactant Tween 80 coated and uncoated chitosan nanoparticle containing lamivudine were prepared for targeted delivery to the brain [78]. The system showed a very good stability for 60 days. In particular, the Tween 80 coated nanoparticles have shown to be efficient and cheaper carrier for targeted delivery of lavimudine to the brain for HIV associated CNS disorders. Squalene, a natural terpenoid; when conjugated with nucleoside analogs have shown to afford amphiphilicprodrugs able toself assembling in water with nanoassemblies of $300 \mathrm{~nm}$ size. This process, called saquenoylation, allows synergistic effects of both the prodrug and nanocarrier [79]. Hiliareuand co-workers showed that saquenoylated NNRTI such as dideoxycytodine and didanosine, when incubated in HIV infected peripheral blood mononuclear cells (PBMCs) enhanced the antiviral delivery of the drug [80]. The conjugated systems orally administered in rats exhibited increased levels of drugs in plasma and target tissues. Moreover, an improved bioavailability and a significantly increased anti-HIV efficacywere reported for these systems. Jain and co-workers explored the use of mannosylated gelatin nanoparticles for the selective delivery of an antiHIV drug, didanosine, to the target organs [81]. Them annosylated gelatin nanoparticles (MN-G-NPs), prepared using a two-step desolvationtechnique, were coupled with mannose using the amino group of gelatin present on the surface of nanoparticles. The cellular uptake by MN-G-NPs was 2.7 times more as comparedwith G-NPs. The results of this study demonstrated that coupling of the nanoparticles with mannose significantly enhanced the lung, liver, and lymph nodes uptake of drug, which is reflected in the recovery of a higher percentage of the dose from these organs following administration of MN-G-NPs in comparison to noncoupled G-NPs or free drug. Low molecular weight chitosan nanoparticles were also investigated as potential drug delivery system of stavudine [82]. The drug entrapment efficiency was found to be near $83 \%$ and in vitro release studies revealed that the rate of drug release was $93 \%$ in 24 hours. The results of this study suggest that chitosan polymer based nanoparticulate formulations are potential means to achieve release of stavudine for the prolonged period of time for effective therapy.

\section{Dendrimers}

Dendrimers are a versatile class of regularly-branched macromolecules with unique structural and topologic features. They are characterized by very small size, typically less than $100 \mathrm{~nm}$, narrow molecular weight distribution, and relative ease of incorporation of targeting ligands $[12,83]$. These features make them potential and fascinating nanoparticles for the delivery of antiretroviral drugs. Unlike natural or synthetic polymers they possess highly branched three-dimensional architecture and are characterized by the presence of three different topologic sites such as the core, interior layers, and multifunctional surface $[83,84]$. The polyfunctional core, surrounded by several layers of highly branched repeating units, such as polyethers, porphyrins, polyamidoamines, polyphenyls, and polyamino acids has the ability to encapsulate several chemical moieties. The multivalent surface interacts with the external environment with several functional groups. The phisicochemical properties of dendrimers can 
be controlled during synthesis by selecting the core groups, the extent of branching, and the nature and/or number of functional groups on the surface. Dendrimers have been used as carriers of antiretroviral peptides and genes for HIV inhibition and more surprisingly, many recent studies showed that they themselves can be used as antiretroviral agents $[83,85,86]$. Dutta and coworkers loaded lamivudine into mannose-capped poly (propyleneimine) dendrimers [87]. The authors reported a significant increase in antiretroviral activity, cellular uptake, and reduced cytotoxicity with respect to the the free drug. Moreover, the specific combination between mannose and ConA, a well-investigated lectin, was detected through in vitro agglutination assay demostrating that the mannose conjugation enabled the targeted delivery of the lamivudine-loaded dendrimers to macrophages containing lectin receptors on their surface. The same research group prepared efavirenz loaded tufstin conjugated $5^{\text {th }}$ generation poly (propyleneimine) dendrimers (TuPPI) [88]. Tuftsin is a natural macrophage activator tetrapeptide (Thr-Lys-Pro-Arg) able to bind specifically to mononuclear phagocytic cells enhancing their phagocytic activity. The authors reported that the dendrimer system is able toprolong the in vitro drug release up to $144 \mathrm{hr}$ with respect to $24 \mathrm{~h}$ of the PPI polymer. Moreover, a 34.5 times higher cellular uptake and reduced viral load by $99 \%$ at a concentration of $0.625 \mathrm{ng} / \mathrm{ml}$ was reported; this activity was more significant in HIV infected macrophages than uninfected cells. In a similar study the same authors prepared t-Boc-glycine conjugated PPI dendrimer (TPPI) and mannose conjugated dendrimer [89]. The mannose conjugated dendrimer showed a 12 times higher increase in cellular uptake of efavirenz by monocyte/macrophage cells with respect to the free drug

\section{Liposomes}

Liposomes are vesicular carriers consisting of phospholipid bilayers surrounding an aqueouscore. The aqueous core can be used to encapsulate hydrophilic drugs while hydrophobic and amphiphilic drugs can be solubilized within the phospholipid bilayers. There are three types of liposomes: small unilamellar vesicles, large unilamellar vesicles, and multilamellar vesicles. Their size ranges from 20 to $30 \mathrm{~nm}$ to several microns and depends upon the type of process and constituent lipid of the liposomes. Liposomes are generally prepared from natural as well as synthetic phospholipids and cholesterol, and may also include other lipids and proteins [90-92]. The unique and advantageous beneficial aspect of liposomes lies in their recognition as a foreign entity by the cells of the mononuclear phagocytic system (MPS), such as the monocytes/macrophages. Since HIV mainly residesin the macrophages and MPS of the body, the liposome based nanoformulations of antiretrovirals can substantially reduce the side effects of the drugs both in vitro and in vivo. Liposomes has been mostly used for the delivery of hydrophobic anti HIV/ AIDS drugs and in thelast two decades many studies reported the liposomaldelivery of anti-HIV/AIDS drugs like zidovudine, didanosine andzalcitabine. Broadly, there are four types of the liposomes mainly studied for the anti-HIV/AIDS drug delivery; these are cationic, anionic, sterically stabilized and immunoliposomes [18]. Encapsulated 2',3'-dideoxycytidine-5'-triphosphate in liposomes and compared its antiviral effect with the dideoxycytidine and dideoxycytidine-triphosphate in cultured human monocyte-macrophages infected with HIV-1 [93]. The antiviral effect and bone marrow toxicity of AZT-loaded liposomes in C57BL/6 mice Zidovudine was exploited by Phillips and co-workers [94]. The authors reported an improved antiviral activity in the infected mice, compared to the free drug. Moreover, no bone marrow toxicity and enhanced localization of AZT in liver, spleen and lung was reported. Jain and co-workers investigated AZT-loaded elasticliposomes which were transdermally administered using a skin model [95]. The authors reported a transdermal flux of the liposomal AZT approximately 20times higher than the free drug across rat skin. In a more recent study the same elastic liposomes were PEGylated and the lymphatic targeting of zidovudine was evaluated in vitro and in vivo [96]. A further increase in the transdermal flux of the drug was observed, compared to unmodified ones. Jin et al. synthesized AZT-myristate (AZT-M), a prodrug of AZT that was loaded into the liposomes [97]. Higher levels of the drug were reported following intravenous administration of AZT-Mliposomes compared with AZT solution. Vyasand co-workers investigated a liposomal formulation called 'emulsomes', lipoidal vesicular systems with an internal solid fat core surrounded by a phospholipid bilayer for the AZT delivery in hepatic cells [98]. Ligand conjugated liposomes such as galactosylated and mannosylated coated were also reported for the targeting of AZT especially to the macrophages and lymphatic system [99-101]. The role of the ligand was found to be predominant over the surface charge in the prolonged localization of the drug and an higher cellular uptake, especially in macrophages, was observed. Katragadda and co-workers investigated the macrophage uptake of stavudine in humanmonocyte/macrophage [102]. Exploring the importance of charge on the liposomes in the cellular uptake the authors reported that the uptake of liposomes containing phosphatidylserine was higher than liposomes prepared using dicetyl phosphate. The authors suggested that this difference might be due to the extent of interaction between the charged bilayer and the cells, the extent of interaction being greater inthe case of negatively charged liposomes. Mannosylated anggalactosylated liposomes were also investigated for the delivery of stavudinein order to enhance the stability of liposomes, which is an inherent limitation for these carriers $[103,104]$. In both case an enhanced half-life and residence time of the encapsulated drug was registered with no hematological or hepatic toxicity. The galactosylated liposomes were further radio labeled with 99mTc, the biodistribution was evaluated and the antiretroviral activity was determined using HIV-1-infected MT2 cell line [105]. The scintigraphic imaging and quantitative biodistribution of $99 \mathrm{mTc}$ labeled drug and liposomes reported in this study, showed that liposomal formulations were better taken up by the liver andspleen and an uptake prolonged up to $24 \mathrm{~h}$ thus suggesting a reduced toxicity and target ability ofthe stavudine-loaded liposomes to the MPS. Liposomes have shown toimprove the delivery of didanosine into target tissues and to reduce the toxic side effects associated with its administration. Desormeaux and co-workers investigated the liposomalencapsulation of the didanosine [106]. The authors report a marked improvement of drug biodistribution, especially into the RES organs but a lowering of the antiviral efficacy with respect to the free drug in HIVIIIB-infected U937 cells. In a further study, the same 
authors extended the drug half-life inplasma from $3.9 \mathrm{~h}$ for conventional liposomes to $14.5 \mathrm{~h}$ by incorporating it into sterically stabilized liposomes [107]. Kompella and co-workers evaluated the effect of didanosine-loaded neutral liposomes on corneal and conjunctivital permeability and report a permeability coefficient, initial flux and tissue levels of the drug at the end of the transport lower in the presence of liposomal formulations [108]. Lalanne et al. investigated didanosine and didanosine monophosphate encapsulated as pro-drug into liposomes in order to bypassthe hepatic first-pass metabolism. The synthesized formulations displayed antiviral activity and enhancement of the drug activity against HIV-1 in in vitro infected cell cultures [109]. In a further study, the same systems were developed as afreeze-dried liposomal formulation for gastro resistant capsules in order to protect the drug from acid degradation [110]. The authors reported a maintained chemical integrity of the pro-drug after the freeze drying of the liposomal formulation. Zalcitabine represets one of the earliest drugs encapsulated in liposomes. Kim and co-workers investigated multi-vesicular liposomes for the delivery of the drug into the cerebrospinal fluid in Sprague-Dawley rat model [111]. Exponentially increased drug level within the CNS with a halflife of $1.1 \mathrm{~h}$ for the non-encapsulated drug was reported and a remarkably $23 \mathrm{~h}$ value for the liposome-encapsulated one. Makabi-Panzu et al. investigated the cellular accumulation, tissue distribution, and antiviral activity of free and liposomal zalcitabinein RAW264.7 and U937 cell lines and reported a significantly higher uptake of the liposomal form was observed in both cell lines [112]. In a further study, the same research team reported that a high intracellular uptake of zalcitabine was facilitated by the anionic nature of the liposomes [113]. Studies have been performed in order to overcome the phosphorylation step which is not feasible due to the presence of phosphatases which hydrolyse nucleotides into the corresponding nucleosides and to the poor permeability of cell membranes to the phosphatase form [114]. Thus, the phosphorylated form of zalcitabin was employed in order to overcome these limitations and to obtain site specific delivery [93]. This nanoformulation was investigated in humanmonocyte/macrophages infected with HIV-1. The authors reported that the free drug was dephosphorylated before entering the cells, while liposomalzalcitabine-TP remained stable over days [115]. Ramana et al developed nepiravine (NVP) loaded liposomal formulation and studied its different parameters [116]. The formulation has an efficient targeted delivery of the anti-retrovirals to the selected compartments and cells with reduced systemic toxic side effects. Several disadvantages limit the use of liposomes in antiretroviral drug delivery. The main limit is the hydrophilic drug-loading capacity of liposomes, due to the small volume of the core (approximately $15 \mu \mathrm{L}$ ); moreover, another challenging issue is the longtermphysical and biologic stability of these delivery systems which precludes their use for sustained drug delivery applications.

\section{Miscellaneous}

Other than the HIV-1 nanotherapeutics above discussed, different types and modifications of carriers have been investigated for the delivery of antiretroviral drugs. Among them, cyclodextrins represent a group of naturally occurring cyclic oligosaccharides composed of $(1,4)$-linked $\alpha$-D-glucopyranose units. Since cyclodextrins are hydrophobic inside and hydrophilic outside, they can form complexes with hydrophobic guest molecules. This ability was used to enhance the solubility of lipophilic antiretroviral drugs, as well as to protect them from external degradation. Sathigari and co-workers investigated the ability of several classes of cyclodextrins, including $\beta$-cyclodextrin, methyl- $\beta$-cyclodextrin, and2-hydroxypropyl- $\beta$-cyclodextrin, to improve the solubility of the hydrophobic efavirenz [117]. The authors reported that hydroxypropyl- $\beta$-cyclodextrin and methyl- $\beta$-cyclodextrin complexed with the drug showed faster in vitro dissolution rate profiles compared with the free efavirenz. Polymeric micelles composed of block copolymers have been used for improving aqueous solubility, membrane permeability, and site-specific delivery of several drugs. They are constituted by a core shell structure usually derived from polymers, such as propylene oxide, aspartic acid, L-lysine, and caprolactone which constitute the hydrophobic block and by the shell composed of a hydrophilic block derived from polymers such as polyethyleneiminepolyvinyl alcohol, and polyethyleneoxide [118]. These micelles can be considered as amphiphilic surfactant molecules that spontaneously aggregate in water into a spherical vesicle the center of which is the hydrophobic core. Depending on the polarity of the drug, it may be entrapped in the core, shell, or at the interface. Pluronics such as P85, are FDA-approved and are the most common block copolymers for the preparation of polymeric micelles used for drug delivery and targeting [119]. Batrakova and co-workers have investigated the coadministration of antiretroviral drugs such as zidovudine, nelfinavir, and lamivudine with P85 and reported an enhancement of the drugs permeability in vitro in bovine brain microvessel endothelial cells and macrophages [120]. The enhancement of the drugs efficacy upon co-administration with P85 was demonstrated in vivo in a severe combined immunodeficiency mousemodel of HIV-1 encephalitis [121]. Even if specific ligands for HIV-infected cells, such asgalactose and lactose units, can be attached to the surface of the polymeric micelles to achieve drug targeting, their biological stability and the slower rate of dissociation, allowing retention of loaded drugs, remain issues, limiting their use for sustained drug delivery applications. Cell-based nanoformulations such as macrophage-based drug delivery system seem to be an efficient and promising drug delivery approach and have been exploreded for the protease inhibitor indinavir [122]. The interest for macrophagesis due to their ability to enter into tissues and anatomic sites with limited access to antiretroviral drugs and hence, to the possibility to use them as transporters for antiretroviral drugs. A combination of indinavir, ritonavir and efavirenz loaded lipid nanoparticles were packaged into the human macrophages [123]. The antiretroviral nanoparticles present in the cytoplasmic vesicles of the macrophages released the drugs for two weeks; moreover, a dose-dependent reduction of viral replication and HIV-1 p24 antigen were observed. Few other nanocarriers such as gold nanoparticles, silver nanoparticles, aptamers, and carbon nanotubes have also been explored for the targeted drug delivery in the field of HIV research. Among them, carbon nanotubes have shown promise as anti-HIV-1 therapeutics. These carbon nanomaterials offer potential advantages over the more widely studied nanoparticle systems including their ability to cross cellular membranes and shuttle drugs, biomolecules 
including DNA, small interfering RNA (siRNA) and proteins, into various types of cells such as cancer cells and T cells [124-127]. Their multimodal conjugation which allows the insertion of more than one type of functional group to the carbon nanotube surface, may be a key property that establishes the superiority of nanopharmaceuticals over conventional agents; in addition, the presence of iron nanoparticles often encapsulated inside the carbon nanotubes allow their use as powerful magnetic carriers in drug delivery and in a range of other magnetic therapies [128]. Single-walled nanotubes were shown to deliver CXCR4 and CD4 specific siRNA to human T cells and peripheral blood mononuclear cells [127]. Up to 90\% knockdown of CXCR4 receptors and up to $60 \%$ knockdown of CD4 expression on T cells was observed while the knockdown of CXCR4 receptors on peripheral blood mononuclear cells was as high as $60 \%$. Multiwalled carbon nanotubes conjugated with lamivudine and other antiretroviral agents have been investigated as anti HIV agent [20]. From this study emerged the pivotal role of the physical chemical properties of these nanosystems, which critically influence the biological interactions; good antiviral activity was, in fact, exerted by the more highly hydrophilic and dispersible samples. The results obtained in these studies could represent an important starting point for future investigation on the use of CNT-based nanomaterials for the treatment of HIV infection.

\section{Conclusion}

AIDS and HIV infection have reached pandemic levels in many parts of the world. Due to the complexities of virus infection cycle and the targets for delivery of antiretroviral drugs, more efficient drug delivery systems are needed. Several nanocarriers have been investigated in order to enhance the effective delivery of antiretroviral drugs for HIV prevention and therapy. Among these, polymeric nanoparticles, dendrimers, liposomes, and various drug conjugates have been reported. These nanotechnology carriers are able to deliver the antiretroviral agents in a controlled and/or targeted manner thereby increasing the drug bioavailability and residence time at target sites with a considerable improvement in quality of HIV patients. These nanotechnology-based drug delivery systems have the potential to completely eradicate viral load from the reservoir sites, not achievable by the free drugs in adequate concentrations. All the above-mentioned studies are in various preclinical stages and a great amount of both experimental and clinical validation needs to be done before these HIV nanotherapeutics could be used in clinics.

\section{References}

1. De Cock KM, Jaffe HW, Curran JW (2012) The evolving epidemiology of HIV/AIDS. AIDS 26: 1205-13.

2. Connor RI, Paxton WA, Sheridan KE, Koup RA (1996) Macrophages and CD4+ T lymphocytes from two multiply exposed, uninfected individuals resist infection with primary non-syncytium-inducing isolates of human immunodeficiency virus type 1. J Virol 70: 8758-64.

3. Liu R, Paxton WA, Choe S, Ceradini D, Martin SR, et al. (1996) Homozygous defect in HIV-1 coreceptor accounts for resistance of some multiply exposed individuals to HIV-1 infection. Cell 86: 367-77.

4. Gupta RK, Van de Vijver DAMC, Manicklal S, Wainberg MA (2013) Evolving uses of oral reverse transcriptase inhibitors in the HIV-1 epidemic: from treatment to prevention. Retrovirology 10: 82 .

5. Achhra AC, Boyd MA (2013) Antiretroviral regimens sparing agents from the nucleoside(tide) reverse transcriptase inhibitor class: a review of the recent literature. AIDS Res Ther 10: 33 .

6. O’Brien WA (2000) Resistance against Reverse Transcriptase Inhibitors. Clini Infec Dise 30: 185-92.

7. Paraschiv S, Otelea D, Baicus C, Tinischi M, Costache M, et al. (2009) Nucleoside reverse transcriptase inhibitor resistance mutations in subtype F1 strains isolated from heavily treated adolescents in Romania. Int J Infect Dis 13: 81-9.

8. Wood E, Hogg RS, Lima VD, Kerr T, Yip B, et al. (2008) Highly active antiretroviral therapy and survival in HIV infected injection drug users. JAMA 300: 550-4. 9. Puhan MA, Van Natta ML, Palella FJ, Addessi A, Meinert C, et al. (2010) Excess mortality in patients with AIDS in the era of highly active antiretroviral therapy: temporal changes and risk factors. Clin Infect Dis 51: 947-56.

10. Sharma R, Jhorar R, Goyal K, Kumar R, Sharma AK (2014) Nanotechnological interventions in HIV drug delivery and therapeutics. Biointerface Res Appl Chem 4: 820-31.

11. Vedha Hari BN, Devendharan K, Narayanan N (2013) Approaches of Novel drug delivery systems for Anti-HIV agents. Int J Drug Dev Res 5: 16-24.

12. Mallipeddi R, Rohan LC (2010) Progress in antiretroviral drug delivery using nanotechnology. Int J Nanomed 5: 533-47.

13. das Neves J, Amiji MM, Bahia MF, Sarmento B (2010) Nanotechnology-based systems for the treatment and prevention of HIV/AIDS. Adv Drug Deliv Rev 62: 458-77.

14. Mahajan SD, Aalinkeel R, Law W-C, Reynolds JL, Nair BB, Sykes DE et al. (2012) Anti-HIV-1 nanotherapeutics: promises and challenges for the future. Int J Nanomed 7: 5301-14.

15. Ojewole E, Mackraj I, Naidoo P, Govender T (2008) Exploring the use of novel drug delivery systems for antiretroviral drugs. Eur J Pharm Biopharm 70: 697710.

16. Vyas TK, Shah L, Amiji MM (2006) Nanoparticulate drug carriers for delivery of HIV/ AIDS therapy to viral reservoir sites. Expert Opin Drug Deliv 3: 613-28.

17. Shahiwala A, Amiji MM (2007) Nanotechnology-based delivery systems in HIV/AIDS therapy. Future HIV Ther 1: 49-59.

18. Lanao JM, Briones E, Colino CI (2007) Recent advances in delivery systems for anti-HIV1 therapy. J Drug Target 15: 21-36.

19. Govender T, Ojewole E, Naidoo P, Mackraj I (2008) Polymeric nanoparticles for enhancing antiretroviral drug therapy. Drug Deliv 15: 493-501.

20. Iannazzo D, Pistone A, Galvagno S, Ferro S, De Luca L, et al. (2015) Synthesis and anti-HIV activity of carboxylated and drug-conjugated multi-walled carbon nanotubes. Carbon 82: 548-61.

21. Vyas TK, Shah L, Amiji MM (2006) Nanoparticulate drug carriers for delivery of HIV/AIDS therapy to viral reservoir sites. Expert Opin Drug Deliv 3: 613-28.

22. Kinch MS, Patridge E (2014) An analysis of FDA-approved drugs for infectious disease: HIV/AIDS drugs. Drug Discovery Today 19: 1510-3.

23. Arts EJ, Hazuda DJ (2012) HIV-1 Antiretroviral Drug Therapy. Cold Spring Harb Perspect Med 2: a007161.

24. Sharma M, Walmsley SL (2014) Antiretroviral therapy in HIV/AIDS. Expert Opin Pharmacother 15: 395-405. 
25. Piperno A, Giofrè SV, Iannazzo D, Romeo R, Romeo G, et al. (2010) Synthesis of C-4‘Truncated Phosphonated Carbocyclic 2‘-Oxa-3‘-azanucleosides as Antiviral Agents. J Org Chem 75: 2798-805.

26. Romeo R, Giofrè SV, Macchi B, Balestrieri E, Mastino A, et al. (2012) Truncated Reverse Isoxazolidinyl Nucleosides: A New Class of Allosteric HIV-1 Reverse Transcriptase Inhibitors. Chem Med Chem 7: 565-9.

27. Romeo R, Carnovale C, Giofrè SV, Romeo G, Macchi B, et al. (2012) Truncated phosphonated C-1'-branched N,O-nucleosides: A new class of antiviral agents. Bioorg Med Chem 20: 3652-7.

28. Romeo R, Carnovale C, Giofrè SV, Monciino G, Chiacchio MA, et al. (2014) Enantiomerically Pure Phosphonated Carbocyclic 2'-Oxa-3'-Azanucleosides: Synthesis and Biological Evaluation. Molecules 19: 14406-16.

29. Esposito F, Corona A, Tramontano E (2012) HIV-1 Reverse Transcriptase Still Remains a New Drug Target: Structure, Function, Classical Inhibitors, and New Inhibitors with Innovative Mechanisms of Actions. Mol Biol Int dx.doi.org/10.1155/2012/586401.

30. Mehellou Y, de Clercq E (2010) Twenty-six years of anti-hiv drug discovery: Where do we stand and where do we go? J Med Chem 53: 521-38.

31. Romeo G, Giofré SV, Piperno A, Romeo R, Chiacchio MA (2009). Synthesis of N,O-homonucleosides with high conformational freedom. Arkivoc (viii): 168-76.

32. Romeo R, Giofrè SV, Iaria D, Sciortino MT, Ronsisvalle S, et al. (2011) Synthesis of 5-Alkynyl Isoxazolidinyl Nucleosides. Eur J Org Chem 28 : 5690-5.

33. Romeo R, Giofrè SV, Garozzo A, Bisignano B, Corsaro A, et al. (2013) Synthesis and biological evaluation of furopyrimidine N,O-nucleosides. Bioorg Med Chem 21: 5688-93.

34. Romeo R, Giofrè SV, Carnovale C, Campisi A, Parenti R, et al. (2013) Synthesis and Biological Evaluation of 3-Hydroxymethyl-5-(1H-1,2,3-Triazol) Isoxazolidines. Bioorg Med Chem 21: 7929-37.

35. Romeo R, Navarra M, Giofrè SV, Carnovale C, Cirmi S, et al. (2014) Synthesis and biological activity of new arenediyne-linked isoxazolidines. Bioorg Med Chem 22: 3379-85

36. Romeo R, Giofrè SV, Carnovale C, Chiacchio MA, Campisi A, et al. (2014) Synthesis and Biological Activity of Triazole-Appended N,O-Nucleosides. Eur J Org Chem 25: 5442-7.

37. Chiacchio U, Corsaro A, Giofrè S, Romeo G (2013) Isoxazolidinyl Nucleosides, chapter 17 pp 781-818 in Chemical Synthesis of Nucleoside Analogues, Edited by Pedro Merino, Wiley-VCH Verlag GmbH \& Co, University of Liverpool UK.

38. Giofrè SV, Romeo R, Chiacchio MA (2014) Phosphonated Isoxazolidinyl Nucleosides, a New Class of Modified Nucleosides. EMBJ 9: 45-55.

39. Romeo R, Carnovale C, Giofrè SV, Chiacchio MA, Garozzo A, et al. (2015) C-5'-Triazolyl-2'-oxa-3'-aza-4'a-carbanucleosides: Synthesis and biological evaluation. Beilstein J Org Chem 11: 328-34.

40. Giofrè SV, Romeo R, Carnovale C, Mancuso R, Cirmi S, et al. (2015) Synthesis and biological properties of 5-(1H-1,2,3-Triazol-4-yl)isoxazolidines: A New Class of C-Nucleosides. Molecules 20: 5260-75.

41. Sarafianos SG, Marchand B, Das K, Himmel DM, Parniak MA, et al. (2009) Structure and function of hiv-1 reverse transcriptase: Molecular mechanisms of polymerization and inhibition. J Mol Biol 385: 693-713.

42. Iyidogan P, Anderson KS (2014) Current Perspectives on HIV-1 Antiretroviral Drug Resistance Viruses 6: $4095-139$.

43. Xia Q, Radzio J, Anderson KS, Sluis-Cremer N (2007) Probing nonnucleoside inhibitor-induced active-site distortion in HIV-1 reverse transcriptase by transient kinetic analyses. Protein Sci 16: 1728-37.

44. Martins S, Ramos MJ, Fernandes PA (2008) The current status of the NNRTI family of antiretrovirals used in the HAART regime against hiv infection. Curr Med Chem 15: 1083-95.

45. Hu Z, Kuritzkes DR (2014) Altered viral fitness and drug susceptibility in human inmmunodeficiency virus type 1 (HIV-1) carrying mutations that confer resistance to non-nucleoside reverse transcriptase and integrase strand-transfer inhibitors. J Virol 88: 9268-76.

46. Young SD, Britcher SF, Tran LO, Payne LS, Lumma WC, et al. (1995) L-743, 726 (DMP-266): A novel, highly potent nonnucleoside inhibitor of the human immunodeficiency virus type 1 reverse transcriptase. Antimicrob Agents Chemother 39: 2602-5.

47. Andries K, Azijn H, Thielemans T, Ludovici D, Kukla M, et al. (2004) TMC125, a novel next-generation nonnucleoside reverse transcriptase inhibitor active against nonnucleoside reverse transcriptase inhibitor-resistant human immunodeficiency virus type 1. Antimicrob Agents Chemother 48: 4680-6.

48. Richman DD (2001) HIV chemotherapy. Nature 410: 995-1001.

49. Richman DD, Margolis DM, Delaney M, Greene WC, Hazuda D, et al. (2009) The challenge of finding a cure for HIV infection. Science 323: $1304-7$.

50. Marsden MD, Zack JA (2009) Eradication of HIV: Current challenges and new directions. J Antimicrob Chemother 63: 7-10.

51. McGee B, Smith N, Aweeka F (2006) HIV pharmacology: Barriers to the eradication of HIV from the CNS. HIV Clin Trials 7: $142-53$.

52. Wan L, Pooyan S, Hu P, Leibowitz MJ, Stein S, et al. (2007) Peritoneal macrophage uptake, pharmacokinetics and biodistribution of macrophage-targeted pegfmlf (n-formyl-methionyl-leucylphenylalanine) nanocarriers for improving HIV drug delivery. Pharm Res 24: 21109.

53. Lamers SL, Salemi M, Galligan DC, Oliveira TD, Fogel GB, et al. (2009) Extensive HIV-1 intra-host recombination is common in tissues with abnormal histopathology. PLoS One 4: E5065.

54. Zhang J, Li S, Li X (2009) Polymeric nano-assemblies as emerging delivery carriers for therapeutic applications: A review of recent patents. Recent Pat Nanotechnol 3: 225-31.

55. Elsabahy M, Wooley KL (2012) Design of polymeric nanoparticles for biomedical delivery applications. Chem Soc Rev 41: 2545-61.

56. Basu S, Mukherjee B, Chowdhury SR, Paul P, Choudhury R, et al. (2012) Colloidal gold-loaded, biodegradable, polymer-based stavudine nanoparticle uptake by macrophages: an in vitro study. Int J Nanomed 7: 6049-61.

57. Kuo YC (2005) Loading efficiency of stavudine on polybutylcyanoacrylate and methylmethacrylate-sulfopropylmethacrylate copolymer nanoparticles. Int J Pharm 290: 161-72.

58. Kuo YC, Chen HH (2006) Effect of nanoparticulate polybutylcyanoacrylate and methylmethacrylate-sulfopropylmethacrylate on the permeability of zidovudine and lamivudine across the in vitro blood-brain barrier. Int J Pharm 327: 160-9.

59. Kuo YC, Su FL (2007) Transport of stavudine, delavirdine, and saquinavir across the blood-brain barrier by polybutylcyanoacrylate, methylmethacrylate- sulfopropylmethacrylate, and solid lipid nanoparticles. Int J Pharm 340: 143-52.

60. Evrim AT, Özge I, Tamer B (2009) Studies on transdermal delivery enhancement of zidovudine. AAPS Pharm Sci Tech 10: 88-97.

61. Destache CJ, Belgum T, Goede M, Shibata A, Belshan MA (2010) Antiretroviral release from poly(DL-lactide-co-glycolide) nanoparticles in mice. J Antimicrob Chemother 65: 2183-7. 
62. Dembri A, Montisci MJ, Gantier JC, Chacun H, Ponchel G (2001) Targeting of 3囚-azido 3囚-deoxythymidine (AZT)-loaded poly(isohexylcyanoacrylate) nanospheres to the gastrointestinal mucosa and associated lymphoid tissues. Pharm Res 18: 467-73.

63. Lobenberg R, Maas J, Kreuter J (1998) Improved body distribution of 14C labelled AZT bound to nanoparticles in rats determined by radioluminography. J Drug Target 5: 171-9.

64. Carvalho FC, Sarmento VH, Chiavacci LA, Barbi MS, Gremião MP (2010) Development and In Vitro Evaluation of Surfactant Systems for Controlled Release of Zidovudine. J Pharm Sci 99: 2367-74.

65. Mainardes RM, Gremião MP (2012) Nanoencapsulation and Characterization of Zidovudine on Poly(L-lactide) and Poly(L-lactide)-Poly(ethylene glycol)Blend Nanoparticles. J Nanosci Nanotechnol 12: 8513-21.

66. Mainardes RM, Gremião MP, Brunetti IL, da Fonseca LM, Khalil NM (2009) Zidovudine-loaded PLA and PLA-PEG blend nanoparticles: Influence of polymer type on phagocytic uptake by polymorphonuclear cells. J Pharm Sci 98: 257-67.

67. Wang B, Chen GQ, Mao ZW, Zhang YY, Yu DH, et al. (2012) Preparation and cellular uptake of PLGA particles loaded with lamivudine. Chin Sci Bull 57: 3985-93.

68. Tamizhrasi S, Shukla A, Shivkumar T, Rathi V, Rathi JC (2009) Formulation and evaluation of lamivudine loaded polymethacrylic acid nanoparticles. Int J PharmTech Res 1: 411-5.

69. Baert L, van't Klooster G, Dries W, François M, Wouters A, et al. (2009) Development of a long-acting injectable formulation with nanoparticles of rilpivirine (TMC278) for HIV treatment. Eur J Pharm Biopharm 72: 502-8.

70. Van 't Klooster G, Hoeben E, Borghys H, Looszova A, Bouche MP, et al. (2010) Pharmacokinetics and disposition of rilpivirine (TMC278) nanosuspension as a long-acting injectable antiretroviral formulation. Antimicrob Agents Chemother 54: 2042-50.

71. Kuo YC, Lin PI, Wang CC (2011) Targeting nevirapine delivery across human brain microvascular endothelial cells using transferrin-grafted poly(lactide-coglycolide) nanoparticles. Nanomedicine 6: 1011-26.

72. Shegokar R, Singh KK (2011) Surface modified nevirapine nanosuspensions for viral reservoir targeting: In vitro and in vivo evaluation. Int J Pharmaceutics 421: 341-52.

73. Destache CJ, Belgum T, Christensen K, Shibata A, Sharma A, et al. (2009) Combination antiretroviral drugs in PLGA nanoparticle for HIV-1. BMC Infect Dis 9: 198.

74. Shibata A, McMullen E, Pham A, Belshan M, Sanford B, et al. (2013) Polymeric nanoparticles containing combination antiretroviral drugs for HIV Type 1 treatment. AIDS Res Hum Retroviruses 29: 746-55.

75. Das Neves J, Araújo F, Andrade F, Michiels J, Ariën KK, et al. (2013) In Vitro and Ex Vivo Evaluation of Polymeric Nanoparticles for Vaginal and Rectal Delivery of the Anti-HIV Drug Dapivirine. Mol. Pharmaceutics 10: 2793-807.

76. Ramana LN, Sharma S, Sethuraman S, Ranga U, Krishnan UM (2014) Evaluation of chitosan nanoformulations as potent anti-HIV therapeutic systems. Biochim Biophys Acta 1840: 476-84.

77. Nesalin JAJ, Smith AA (2011) Formulation and evaluation of nanoparticles containing lamivudine. Inventi: ndds/112/11.

78. Dhanya KP, Santhi K, Dhanaraj SA, Sajeeth CI (2011) Formulation and evaluation of chitosan nanospheres as a carier for the targeted delivery of lamivudine to the brain. Pharmacie Globale 2: 5.

79. Couvreur P, Stella B, Reddy LH, Hillaireau H, Dubernet C, et al. (2006) Squalenoyl nanomedicines as potential therapeutics. Nano Lett 6: 244-8.

80. Hillaireau H, Dereuddre-Bosquet N, Skanji R, Bekkara-Aounallah F, Caron J, et al. (2013) Anti-HIV efficacy and biodistribution of nucleoside reverse transcriptase inhibitors delivered as squalenoylated prodrug nanoassemblies. Biomaterials 34: 4831-8.

81. Jain SK, Gupta Y, Jain A, Saxena AR, Khare P, et al. (2008) Mannosylated gelatin nanoparticles bearing an anti-HIV drug didanosine for site-specific delivery. Nanomed Nanotech Biol Med 4: 41-8.

82. Karthikeyan D, Srinivas M, Kumar CS (2013) Formulation and Evaluation of Stavudine Nanoparticles. IJNTPS 3: 24-32.

83. Peng J, Wu Z, Qi X, Chen Y, Li X (2013) Dendrimers as potential therapeutic tools in HIV inhibition. Molecules 18: 7912-29.

84. Svenson S, Tomalia DA (2005) Dendrimers in biomedical applications-reflections on the field. Adv Drug Deliv Rev 57: 2106-29.

85. Bosman AW, Janssen HM, Meijer EW (1999) About dendrimers: Structure, physical properties, and applications. Chem Rev 99: 1665-88.

86. Macri RV, Karlovská J, Doncel GF, Du X, Maisuria BB, et al. (2009) Comparing anti-HIV, antibacterial, antifungal, micellar, and cytotoxic properties of tricarboxylato dendritic amphiphiles. Bioorg Med Chem 17: 3162-8.

87. Dutta T, Jain NK (2007) Targeting potential and anti-HIV activity of lamivudine loaded mannosylated poly (propyleneimine) dendrimer. Biochim Biophys Acta 1770: 681-6.

88. Dutta T, Garg M, Jain NK (2008) Targeting of efavirenz loaded tuftsin conjugated poly (propyleneimine) dendrimers to HIV infected macrophages in vitro. Eur J Pharm Sci 34: 181-9.

89. Dutta T, Agashe HB, Garg M, Balakrishnan P, Kabra M, et al. (2007) Poly (propyleneimine) dendrimer based nanocontainers for targeting of efavirenz to human monocytes/macrophages in vitro. J Drug Target 15: 89-98.

90. Castor TP (2005) Phospholipid nanosomes. Curr Drug Deliv 2: 329-40.

91. Gupta U, Jain NK (2010) Non-polymeric nano-carriers in HIV/AIDS drug delivery and targeting. Adv Drug Deliv Rev 62: 478-90.

92. Voinea M, Simionescu M (2002) Designing of 'intelligent' liposomes for efficient delivery of drugs. J Cell Mol Med 6: 465-74.

93. Szebeni J, Wahl SM, Betageri GV, Wahl LM, Gartner SM, et al. (1990) Inhibition of HIV-1 in monocyte/ macrophage cultures by 2', 3'-dideoxycytidine-5'triphosphate, free and in liposomes, AIDS Res. Hum Retroviruses 6: 691-702.

94. Phillips NC, Skamene E, Tsoukas C (1991) Liposomal encapsulation of 3'-azido-3'- deoxythymidine (AZT) results in decreased bone marrow toxicity and enhanced activity against murine AIDS-induced immunosuppression. J Acquir Immune Defic Syndr 4: 959-66.

95. Jain S, Tiwary AK, Jain NK (2006) Sustained and targeted delivery of an anti-HIV agent using elastic liposomal formulation: mechanism of action. Curr Drug Deliv 3: 157-66.

96. Jain S, Tiwary AK, Jain NK (2008) PEGylated elastic liposomal formulation for lymphatic targeting of zidovudine. Curr Drug Deliv 5: 275-81.

97. Jin SX, Bi DZ, Wang J, Wang YZ, Hu HG, et al. (2005) Pharmacokinetics and tissue distribution of zidovudine in rats following intravenous administration of zidovudine myristate loaded liposomes. Pharmazie 60: 840-3.

98. Vyas SP, Subhedar R, Jain S (2006) Development and characterization of emulsomes for sustained and targeted delivery of an antiviral agent to liver. J Pharm Pharmacol 58: 321-6. 
99. Wu HB, Deng YH, Wang SN, Zhou XY, Wang N, et al. (2007) The distribution of azidothymidine palmitate galactosylated liposomes in mice. Acta Pharm Sin 42: $538-44$.

100. Garg M, Jain NK (2006) Reduced hematopoietic toxicity, enhanced cellular uptake and altered pharmacokinetics of azidothymidine loaded galactosylated liposomes. J Drug Target 14: 1-11.

101. Kaur CD, Nahar M, Jain NK (2008) Lymphatic targeting of zidovudine using surfaceengineered liposomes. J Drug Target 16: 798-805.

102. Katragadda A, Bridgman R, Betageri G (2000) Effect of liposome composition and cholesterol on the cellular uptake of stavudine by human monocyte/ macrophages. Cell Mol Biol Lett 5: 483-93.

103. Garg M, Asthana A, Agashe HB, Agrawal GP, Jain NK (2006) Stavudine-loaded mannosylated liposomes: in-vitro anti-HIV-I activity, tissue distribution and pharmacokinetics. J Pharm Pharmacol 58: 605-16.

104. Garg M, Dutta T, Jain NK (2007) Reduced hepatic toxicity, enhanced cellular uptake and altered pharmacokinetics of stavudine loaded galactosylated liposomes. Eur J Pharm Biopharm 67: 76-85.

105. Garg M, Garg BR, Jain S, Mishra P, Sharma RK, et al. (2008) Radiolabeling, pharmacoscintigraphic evaluation and antiretroviral efficacy of stavudine loaded 99mTc labeled galactosylated liposomes. Eur J Pharm. Sci 33: 271-81.

106. Désormeaux A, Harvie P, Perron S, Makabi-Panzu B, Beauchamp D, et al. (1994) Antiviral efficacy, intracellular uptake and pharmacokinetics of free and liposome-encapsulated 2', 3'-dideoxyinosine. AIDS 8: 1545-53.

107. Harvie P, Desormeaux A, Bergeron MC, Tremblay M, Beauchamp D, et al. (1996) Comparative pharmacokinetics, distributions in tissue, and interactions with proteins of conventional and sterically stabilized liposomes containing 2', 3'-dideoxyinosine blood. Antimicrob Agents Chemother 40: 225-9.

108. Kompella UB, Aukunuru JV, Betageri GV (1999) Effect of neutral liposomes on corneal and conjunctival transport of didanosine. Drug Deliv 6: 9-14.

109. Lalanne M, Paci A, Andrieux K, Dereuddre-Bosquet N, Clayette P, et al. (2007) Synthesis and biological evaluation of two glycerolipidic prodrugs of didanosine for direct lymphatic delivery against HIV. Bioorg Med Chem Lett 17: 2237-40.

110. Lalanne M, Andrieux K, Paci A, Besnard M, Ré M, et al. (2007) Liposomal formulation of a glycerolipidic prodrug for lymphatic delivery of didanosine via oral route. Int J Pharm 344: 62-70.

111. Kim S, Scheerer S, Geyer MA, Howell SB (1990) Direct cerebrospinal fluid delivery of an antiretroviral agent using multivesicular liposomes. J Infect Dis 162: 750-2.

112. Makabi-Panzu B, Lessard C, Perron S, Désormeaux A, Tremblay M, et al. (1994) Comparison of cellular accumulation, tissue distribution, and anti-HIV activity of free and liposomal 2', 3'-dideoxycytidine. AIDS Res Hum Retrovir 10: 1463-70.

113. Makabi-Panzu B, Gourde P, Desormeaux A, Bergeron MG (1998) Intracellular and serum stability of liposomal 2',3'-dideoxycytidine. Effect of lipid composition. Cell Mol Biol 44: 277-84.

114. Rossi L, Brandi G, Schiavano GF, Chiarantini L, Albano A, et al. (1992) In vitro and in vivo toxicity of 2', 3'-dideoxycytidine in mice. Chem Biol Interact 85: 255-63.

115. Oussoren C, Magnani M, Fraternale A, Casabianca A, Chiarantini L, et al. (1999) Liposomes as carriers of the antiretroviral agent dideoxycytidine-50-triphosphate. Int J Pharm 180: 261-70.

116. Ramana LN, Sethuraman S, Ranga U, Krishnan UM (2010) Development of a liposomal nanodelivery system for nevirapine. J Biomed Sci $17: 57$.

117. Sathigari S, Chadha G, Lee YH, Wright N, Parsons DL, et al. (2009) Physicochemical characterization of efavirenz-cyclodextrin inclusion complexes. AAPS Pharm Sci Tech 10: 81-7.

118. Adams ML, Lavasanifar A, Kwon GS (2003) Amphiphilic block copolymers for drug delivery. J Pharm Sci 92: 1343-55.

119. Shaik N, Pan G, Elmquist WF (2008) Interactions of pluronic block copolymers on P-gp efflux activity: Experience with HIV-1 protease inhibitors. J Pharm Sci 97: 5421-33.

120. Batrakova EV, Li S, Miller DW, Kabanov AV (1999) Pluronic P85 increases permeability of a broad spectrum of drugs in polarized BBMEC and Caco-2 cell monolayers. Pharm Res 16: 1366-72.

121. Spitzenberger TJ, Heilman D, Diekmann C, Batrakova EV, Kabanov AV, et al. (2007) Novel delivery system enhances efficacy of antiretroviral therapy in animal model for HIV-1 encephalitis. J Cereb Blood Flow Metab 27: 1033-42.

122. Dou H, Grotepas CB, McMillan JM, Destache CJ, Chaubal M, et al. (2009) Macrophage delivery of nanoformulated antiretroviral drug to the brain in a murine model of neuroAIDS. J Immunol 183: 661-9.

123. Nowacek AS, Miller RL, McMillan J, Kanmogne G, Kanmogne M, et al. (2009) NanoART synthesis, characterization, uptake, release and toxicology for human monocytemacrophage drug delivery. Nanomedicine 4: 903-17.

124. Iannazzo D, Piperno A, Pistone A, Grassi G, Galvagno S (2013) Recent advances in carbon nanotubes as delivery systems for anticancer drugs. Curr Med Chem 20: 1333-54.

125. Cunha C, Panseri S, Iannazzo D, Piperno A, Pistone A, et al. (2012) Hybrid composites made of multiwalled carbon nanotubes functionalized with Fe3O4 nanoparticles for tissue engineering applications. Nanotechnology 23: 465102.

126. Iannazzo D, Piperno A, Ferlazzo A, Pistone A, Milone C, et al. (2012) Functionalization of multi-walled carbon nanotubes with coumarin derivatives and their biological evaluation. Org Biomol Chem 10: 1025-31.

127. Liu Z, Winters M, Holodniy M, Dai H (2007) SiRNA delivery into human T cells and primary cells with carbon-nanotube transporters. Angew Chem Int Ed 46: 2023-7.

128. Santangelo S, Messina G, Donato MG, Lanza M, Milone C, et al. (2006) Low-frequency Raman study of hollow multiwalled nanotubes grown by Fe-catalyzed chemical vapor deposition. J Appl Phys 100: 104311. 


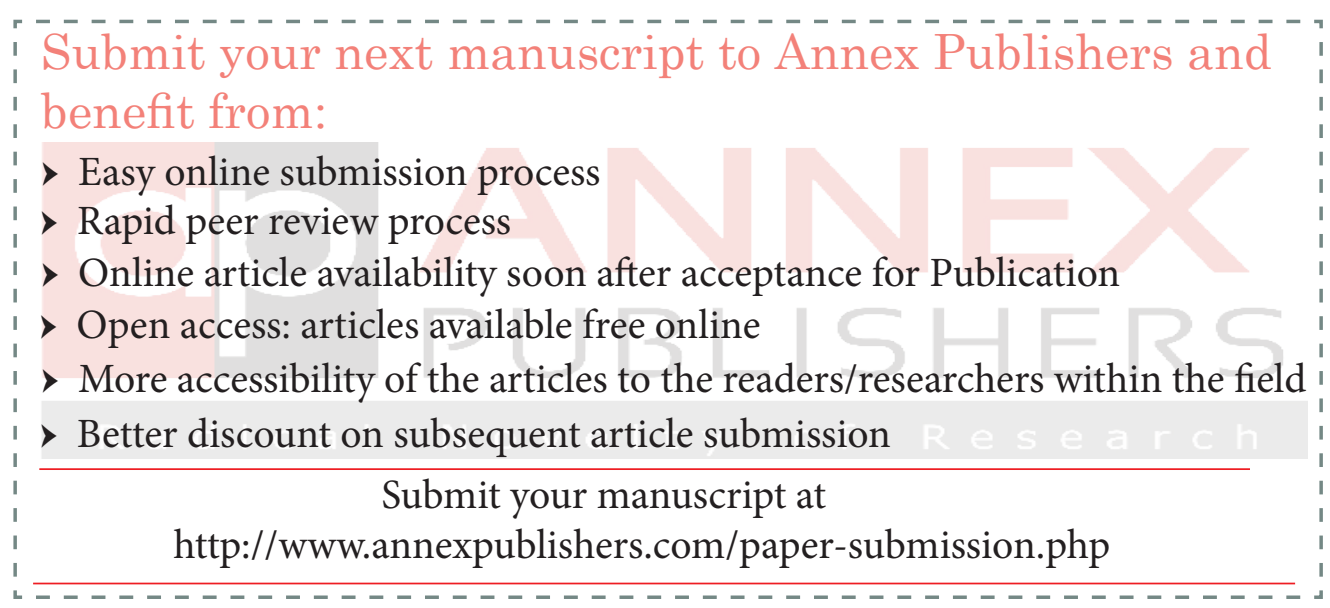

